\title{
La ermita de Santa Eufemia (Cástulo), un caso de experiencia tutelar del patrimonio arqueológico a mediados del siglo XVIII.
}

\author{
The chapel of Santa Eufemia (Castulo), a case of tutelar experience on \\ archaeological heritage in the XVIII mid-century.
}

\author{
Ángela Sánchez López *, Enrique Infante Limón **, \\ Antonio Valiente Romero ***
}

\section{RESUMEN}

Las especiales características del sitio arqueológico de Cástulo, en concreto de la ciudad amurallada, lo convierten en un ejemplo de especial interés para el conocimiento de la concepción que tuvieron la Iglesia y la Corona española, durante las Épocas Medieval y Moderna, de las evidencias materiales del pasado. En el presente artículo constatamos cómo se produjo una confrontación entre el uso simbólico que de dichos elementos había venido haciendo la primera institución y las iniciativas de carácter patrimonialista que promovió la segunda en el siglo XVIII, muy vinculadas a la corriente intelectual ilustrada $y$, en su seno, a la práctica jurídica del regalismo, que chocaba con la mentalidad de expansión patrimonial que venía practicando la Iglesia, al menos desde el siglo V, con respecto a los espacios públicos laicos y paganos. Un buen ejemplo de experiencia tutelar lo encontramos en la actuación que llevó a cabo Carlos Lanci sobre la Ermita de Santa Eufemia, edificación de marcado carácter simbólico, no sólo por su integración en el yacimiento, sino también por la elevada reutilización que, para su fábrica, se hizo de elementos constructivos que remitían a la Antigüedad Clásica. El objetivo del presente artículo ha sido, precisamente, analizar dicho caso, para poner de relieve cómo se procedió, qué resultados se obtuvieron y, por tanto, en qué medida se produjo aquella confrontación entre los intereses de las partes implicadas. Con ello, hemos pretendido realizar una aportación al estudio de la evolución sufrida por el concepto de Patrimonio Arqueológico en nuestro país.

Palabras clave: Cástulo, Ermita de Santa Eufemia, Patrimonio Cultural, Arqueología, Carlos Lanci, Marqués de la Ensenada, Iglesia, Regalismo, llustración.

\begin{abstract}
The special features of the archaeological site of Castulo, particularly in the walled city, makes it an example of special interest for the knowledge of the concept that had both the Church and the Spanish Crown, during the Medieval and Modern Times, of past material evidences. In this article we note how there was a confrontation between the symbolic use of these items carried out by the first institution and the initiatives of patrimonial character promoted by the second in the eighteenth century. These were closely linked to the intellectual current of the Enlightenment and, in its bosom, to the legal practice of royalism, which clashed with the mentality of asset expansion that the church had been practicing at least since the $V$ century, with respect to the lay and pagans public spaces.

A good example of tutelar experience is found in the performance conducted by Carlos Lanci on the Chapel of Santa Eufemia, highly symbolic building, not only for its integration into the site, but also by the high re-use that, for its construction, was made of building blocks that referred to Classical Antiquity. The aim of this article has been precisely analyze this case to highlight how they proceeded, what results were obtained and, therefore, to what extent was this confrontation between the interests of the parties involved. With this, we have tried to make a contribution, to the extent that the conclusions of a particular analysis can afford, the study of the evolution undergone by the concept of archaeological heritage in our country.
\end{abstract}

Keywords: Castulo, Chapel of St. Euphemia, Cultural Heritage, Archaeology, Carlos Lanci, Marques de la Ensenada, Church, Regalism, Enlightenment.

\footnotetext{
* Consejería de Cultura. Delegación Provincial de Jaén.

** Universidad de Sevilla.
} 


\section{INTRODUCCIÓN}

Tradicionalmente se ha considerado que el Patrimonio Cultural no alcanzaría la dimensión moderna que hoy conocemos hasta la Revolución Francesa. Ésta propició una valoración del mismo vinculada a su perfil público y colectivo, potenciando, de este modo, su carácter identitario para las naciones $y$, por tanto, la idea de que era necesaria su institucionalización técnica y jurídica (LLULL PEÑALBA, 2005: p. I 88). Las experiencias tutelares, no obstante, ya se venían produciendo desde el Renacimiento e incluso la Edad Media, pero sería en el siglo XVIII cuando comenzasen a alcanzar verdadero vigor (YÁÑNEZ VEGA, LAVÍN BERDONCES, 1999: pp. 124- I27; MAIER ALLENDE, 2003: pp. 440-446; QUIROSA GARCÍA, 2008: pp. 19-22). En ello jugaron un papel decisivo los conceptos ilustrados, el auge de la práctica del coleccionismo y, muy especialmente, la actividad de las instituciones fundadas en aquellos momentos: gabinetes, academias y, más tarde, museos (LLULL PEÑALBA, 2005: p. 187) '.

En España, la renovación científica y cultural ilustrada vino de la mano de los nuevos monarcas, los Borbones. Éstos, entendiendo que de dicha cuestión derivaría un gran beneficio para el país -pues los intelectuales debían jugar un destacado papel en la renovación del mismo-, promovieron una amplia y burocratizada estructura destinada al fomento de las actividades eruditas (MORA RODRÍGUEZ, 1998: pp. 31-36; LÓPEZ-CORDÓN, 20।0). Es en este contexto en el que debemos situar la fundación de la Real Academia de la Historia, en 1738, y el nuevo cariz que se le otorgó, desde dicha institución, al concepto que se tenía de la Historia. El principal objetivo de los académicos era el de contribuir al realce y al esplendor del reino, mediante una labor que, «desterrando» las fábulas introducidas por los falsos cronicones, condujese al conocimiento «útil» y proporcionase el «beneficio común» de la «iverdad de los sucesos»
(TORTOSA ROCAMORA, MORA RODRÍGUEZ, 1996: p. 193). Ese conocimiento racional y ordenado del pasado debía apoyar, además, la política regalista desarrollada por la nueva dinastía reinante, que buscó en la Historia los fundamentos para legitimar su poder, para defender la primacía de la Corona frente a la Iglesia y, así, proteger sus intereses ante la Santa Sede antes de la firma del Concordato de 1753 (MORA RODRÍGUEZ, 1998: pp. 42-43; LÓPEZ-CORDÓN, 20 I 0: pp. 23-24).

Las iniciativas que se pusieron en marcha a lo largo del siglo, en relación con el estudio del pasado español, la Arqueología y la tutela del Patrimonio, deben ser entendidas desde estos puntos de vista. Es el caso, por ejemplo del inicio de la realización del Diccionario Crítico-Histórico de España o del Tratado de la Cronología de España, así como del impulso y desarrollo de los llamados "viajes literarios", destinados a documentar y recoger testimonios directos del pasado que ayudasen a la construcción de un verdadero discurso histórico (ALMAGRO-GORBEA, MAIER ALLENDE, 2003b; ALMAGRO-GORBEA, 2010 y 2012). El reinado de Fernando VI, en este sentido, fue especialmente fructífero, llevándose a cabo empresas tan interesantes como la dirigida por el Padre Burriel para el reconocimiento de archivos -y así tener argumentos para negociar el Concordato con la Santa Sede-, o el trascendente Viaje de las Antigüedades de España, iniciado en 1752 por Luis José Velázquez, Marqués de Valdeflores (MAIER ALLENDE, 2010 y 20 I2: pp: 340-344). Dentro de este ambiente, el Marqués de la Ensenada desempeñó un importante papel. Por ejemplo, en 1747 comisionó al ingeniero Carlos Luján para que recogiera las antigüedades de Cártama -Málaga-; también dictó la Real Orden del 8 de abril de 1752, sobre la protección y conservación de antigüedades que se hallaren al hacer obras en puertos (QUIROSA GARCÍA, 2008: p. 25 y ss.) y promovió, entre otras cosas, el patrocinio Real del viaje del Marqués de Valdeflores, hasta el

\footnotetext{
I Este autor considera que se produjo ... un proceso de secularización y universalización de la cultura que facilitó la mirada crítica hacia el pasado histórico artístico, cuyos testimonios comenzaron, además, a ser protegidos por leyes más específicas. Las ideas ilustradas, junto con los avances experimentados por las ciencias del conocimiento, colocaron a la cultura en una posición de auténtico protagonismo, convirtiéndola en eje de las conversaciones humanas. Las expediciones científicas, las primeras excavaciones arqueológicas realizadas con criterios rigurosos, y el redescubrimiento de la Antigüedad a través de las corrientes neoclásicas y románticas hicieron que, a lo largo del XVIII, proliferasen un sinfín de actividades practicadas por sociedades filantrópicas y otros círculos eruditos.
} 
punto de ser retirado tras su caída (ALMAGROGORBEA, MAIER ALLENDE, 2003b: pp. 4-8).

Pero lo que a nosotros nos interesa es que, el 14 de julio de 1753, se dictó un Real Decreto que ordenaba

... a los Corregidores, y Justicias del Reino remitan a Madrid y a la casa establecida de geografía todas las piezas de antigüedad que se hallaren, [...] como son estatuas de mármol, bronce $u$ otro metal, rotas o enteras, Pavimentos Mosaicos, o de otra especie, herramientas, o instrumentos de madera, piedra o suela, monedas, o lápidas y lo que de ellas se diga por escritos, tradiciones, o noticias... (QUIROSA GARCÍA, 2008: p. 25 y ss.).

La iniciativa resulta interesante porque, dentro de aquel fervor coleccionista que imperaba en el contexto ilustrado y regalista español, también se pretendía la formación de una colección para la Real Casa Geográfica y Gabinete de Historia Natural (ALMAGRO-GORBEA, MAIER ALLENDE, 2003b: p. 12). La fundación de ésta, en 1752, estuvo estrechamente relacionada con la actividad de Antonio de Ulloa en el marco de los viajes que realizó a Londres y París para el reclutamiento de especialistas extranjeros en Cartografía, Química e Historia Natural (CALATAYUD ARINERO, 1986 y 1988: pp. 42-57; PUIGSAMPER, 1995: p. 5). La norma iba en consonancia con los preceptos que el propio Ulloa había trazado para la nueva institución, pero también, lógicamente, con el concepto de Patrimonio Arqueológico que hemos descrito para la época: los objetos a recoger se valoraban por su carácter de rareza o elemento singular ${ }^{2}$, pero también en función de su antigüedad y en función de la información que aportaban.

Como ponen de manifiesto estas primeras líneas, el tema de la tutela y la gestión del
Patrimonio Monumental y Arqueológico en el siglo XVIII, a nivel de conceptos y normas, ha sido ampliamente tratado. Sin embargo, en muy pocas ocasiones se ha prestado atención a los casos concretos de aplicación y a los conflictos generados por los mismos, sobre todo porque estas incipientes experiencias, en muchos casos, han sido consideradas sólo como la base para el estudio del desarrollo tutelar llevado a cabo en la centuria siguiente. Con este artículo nos proponemos analizar uno de estos casos, derivado de un intento de aplicación del Real Decreto del 14 de julio de I 753 en la ermita de Santa Eufemia de Cástulo, un edificio cristiano ubicado en un yacimiento de especial significación e importancia por su vinculación con la Antigüedad.

\section{LA IGLESIA, SU PATRIMONIO Y LA CRISTIANIZACIÓN DE LOS ESPA- CIOS PÚBLICOS}

La ciudad ibero-romana de Cástulo se sitúa en un ámbito que registra ocupación atrópica ininterrumpida desde finales del III milenio a.C. hasta el siglo $\mathrm{XV}$, momento en que se produce su abandono definitivo. A lo largo de esta extensa historia como ciudad se convertirá, en el II milenio a.C. en un centro destacado en toda la región de Sierra Morena, vinculado a la actividad minera y metalúrgica del cobre, plomo y plata. Su importancia se acrecentará progresivamente hasta que en los siglos VII-VI se convierta en el oppidum más extenso de la Península Ibérica, acuñando incluso su propia moneda. Esta situación favorecerá su marcado protagonismo en la II Guerra Púnica, inicialmente como alidada de Cartago -Anibal contrajo matrimonio con la princesa indígena Hilmice-y posteriormente de Roma, cuando las oligarquías locales de la ciudad suscribieron un pacto con Escipión durante los últimos años del siglo III a.C. (PELLETIER, 1987, pp. 27I-280).

\footnotetext{
2 Los gabinetes de Historia Natural son sin duda los archivos de la naturaleza, en donde la curiosidad registra lo admirable y lo raro que se encuentra en diversas partes del mundo: esta especulación no es suficiente para dejar satisfechos los designios del entendimiento en el empeño de conocer fundamentalmente la causa de la variedad. La naturaleza es admirable en sus producciones, y tal se conoce generalmente; pero el confesarlo así, no la hace más comprensible. Descúbrense los efectos en la diversidad sin alcanzarse el origen; y hay infinidad de maravillas que las perciben los sentidos, sin que el entendimiento se detenga a considerarlas; del mismo modo en otras cosas se detiene poco la reflexión, por no poder encontrar lo que encierran de raro o de particular: naciendo de esto, que continuamente se trabaja en las investigaciones, por cuyo medio se adelantan los descubrimientos aunque sin llegar a ver el fin (PUIG-SAMPER, 1995: pp. I19- I20).
} 
A pesar del severo proceso de abandono que registró la ciudad de Cástulo desde principios de la Edad Media, el área ocupada por el asentamiento nunca perdió su carácter de espacio público, si bien a lo largo del transcurso de los siglos se fue viendo modificado y atenuado.

Hasta finales de la dominación islámica se debió mantener en la ciudad una guarnición armada, pues existen testimonios de confrontaciones militares en la misma -como es el caso de su toma, en 895, por Abd Allah, Ibn al-Saliya- y se tiene constancia de la existencia de habitantes en ella (SALVATIERRA CUENCA, 2001 , pp. 98 y 1 19). A su vez, la continuidad de la funcionalidad militar de la fortificación queda avalada por las excavaciones arqueológicas realizadas en el ámbito Noroeste del Cerro de La Muela durante los años 2008 y 2009. Éstas han puesto de manifiesto que el recinto amurallado de la ciudad se mantuvo en uso y con guarniciones militares, desde los inicios de la dominación islámica o época Emiral, al menos, hasta el período Almohade, lo que sugiere la idea, por tanto, de que las murallas probablemente tuvieron un uso continuado desde la época Ibérica hasta la Almohade (CHOCLÁN SABINA, 2008-2009: pp. 80-1 I0).

Presumiblemente, la caracterización del asentamiento se correspondería con la de los denominados husun, atendiendo a la tipología aportada por Husseín Monés (CASTILLO ARMENTEROS, 1998: p. 128). A su vez, el espacio comprendido en el interior de la muralla del cerro de la Muela pudo ser utilizado como albacar ${ }^{3}$. Una reminiscencia de esto puede ser su caracterización posterior a la conquista cristiana, pues quedó convertido en dehesa comunal, primero de Baeza y después de Linares, población a la que se otorga mediante confirmación de una sentencia real de 1314 , en la que podemos leer:

...y que el rey, por que falló que era así, como es sobredicho, otorgó a los de Linares la Muela de Cazlona, así como sobredicho es.
Y defendió firmemente al concejo de Baeza que ellos ni otros ningunos non fuesen osados ende adelante aquellos embargar, ni de aquellos quebrantar, ni de ellos contradecir [a] ellos en esta razón. Y quales quier que lo hiciesen y que lo pechasen en todo [y por todo]. Y a los de Linares todo el daño doblado (Archivo Municipal de Linares, AML en adelante, CR. 003).

Vuelve a reforzarse, a partir de aquí, la caracterización de espacio público de Cástulo, de manera que, ya bien entrada la Edad Moderna, era necesario el permiso del cabildo de la villa para cualquier aprovechamiento de los recursos situados en la antigua ciudad. Fue el caso, por ejemplo, de Andrés de Lima en I59I:

Otrosi se trató que el concejo ha sido citado por Andrés de Lima, pedrero, que pretende sacar piedras de la Dehesa de Cazlona, que es propios del cabildo, la cual está arrendada, y por ser propia del cabildo cometieron al señor Bernardo Pimentel que se informe de los letrados [...] de la justicia que el cabildo tendrá, mostrándoles el proceso a los letrados, pareciese que si el pleito justo se haga (AML. LA. 0004, fol. 280 v).

Por supuesto, también hubo intentos esporádicos de acotación del terreno de la dehesa, aunque el cabildo nunca lo permitió, preservando así el carácter público de la zona:

En este cabildo se llamaron al licenciado Pedro Palomino y el licenciado Gabriel Delgado, abogados del cabildo, y se les dijo y dio cuenta de que la Dehesa de Cazlona y tierras de labor que se incluyen en la dicha dehesa estaba puesta por nueve años a cuatro mil maravedís y por que se cierre el pasto de las labores, el licenciado Martín impondrá mil maravedís cada año y el personero ha pedido que no se cierre el pasto de las labores, diciendo a los dichos abogados den su parecer, lo que el cabildo deba hacer por ellos, y habiendo los dichos abogados [visto] los títulos de la dicha dehe-

3 Las posiciones de Guichard han sido criticadas fundamentalmente en base a criterios filológicos y etimológicos, defendiéndose que el albacar es exclusivamente un lugar de recogida del ganado... (CASTILLO ARMENTEROS, 1998; p. I30). 
sa y otras escrituras que el cabildo tiene de los heredamientos de Cazlona, dijeron que su parecer es que por todo el año las tierras de labor sean abiertas para que la hierba de ella la pasten los vecinos y que el cabildo no las cierre, y esto dijeron por su parecer y lo firmaron (AML. LA. 0008, fol. 96 v).

Así, los datos nos indican que nos encontramos ante un espacio conceptualizado como lugar de carácter público a lo largo de más de 2.000 años, hecho que, sin duda, debió tener su reflejo en la mentalidad colectiva. Esto debió tener especial incidencia en las leyendas y tradiciones orales, hoy perdidas, que debieron existir en el imaginario social. De ellas debió derivar la denominación de "Cazlona", primero, y "Cardona", posteriormente, para el espacio ocupado por la ciudad, que a su vez dieron nombre a un molino situado en su solar, cuya presencia está constatada documentalmente desde el siglo XVI, aunque su origen sea, posiblemente, muy anterior.

A priori no es posible determinar si este carácter influyó de manera positiva o negativa en la conservación del yacimiento, ya que -mientras pudo haber impedido el desgaste que habría sufrido si hubiese sido utilizado para la realización de actividades agrícolas- su uso comunal derivó en el aprovechamiento como cantera, como hemos visto y como demuestra el material romano reutilizado en edificaciones próximas ${ }^{4}$.

Pero la verdadera importancia de esta caracterización pública, de cara a la cuestión que nos ocupa, radica en la asimilación simbólica que realizaba la Iglesia de este tipo de espacios, algo que tendrá su plasmación en Cástulo, durante el siglo XVII, con la revalorización de la ermita de Santa Eufemia.
En realidad, el origen de la práctica eclesiástica de la cristianización, tanto de espacios de origen pagano como de estructuras y elementos constructivos, se sitúa en la tardoantigüedad, quedando recogida su base teórica en varias fuentes documentales.

San Pedro Crisólogo, en su sermón 5 I (siglo V), ya afirmaba que

Esto es lo que el Señor... respondió a todos... ¿y no iré a los gentiles? Donde [resuena] la voz de un discípulo mío se derrumban los templos, huyen los ídolos, se destruyen las aras, se extinguen las luces, huye todo el poder de los demonios con sus antiguos y aletargados tronos en lamentos, temor y gemidos; se cambian en iglesias los templos, se convierten en altares las aras... (CABALLERO ZOREDA, SÁNCHEZ SANTOS, 1990: p. 432).

Contamos con otro testimonio más tardío (siglo VI) en la carta de Gregorio Magno al Abad Melitón, referida, en este caso concretamente, a los lugares sagrados de los Anglos:

...decidle [a Agustín] ... sobre el tema de los anglos... que los lugares sagrados no deben ser destruidos en absoluto, entre esa misma gente, pero deben ser destruidos los ídolos que en ellos haya. Que bendiga agua y la asperja en los mismos lugares sagrados, que construya altares, que ponga reliquias, porque, si los mismos lugares sagrados están bien construidos, es necesario que olviden el culto al demonio, cambiándole en reverencia al verdadero Dios y concurriendo a los lugares que les son más familiares según acostumbran... (CABALLERO ZOREDA, SÁNCHEZ SANTOS, 1990: p. 433).

\footnotetext{
4 Es muy significativo que, por ejemplo, José Martínez de Mazas, en el capítulo IV de su Descripcion del sitio y ruinas de Castulo y noticias de esta antigua Ciudad en el Reyno de Jaen (1788), refiriéndose a los materiales dispersos del yacimiento, dejase constancia de lo siguiente: Del mismo modo se encuentran cabezas de estatuas de hombres y mujeres que en algún tiempo anduvieron rodando por estos campos y al presente se halla una que se ha vuelto etíope sobre el hogar de la cocina de la Casería inmediata de don Martín Alonso de Quesada, otra mejor y de mármol blanco se ve en una pared que mira al oriente en el Molino de aceite y casería no distante del Hospital de la Concepción de Baeza. Otra mujer o diosa con muchas trenzas en el cabello en el cortijo de Casa Blanca en la pared que mira al norte. Y finalmente otra semejante a esta aunque más desfigurada en la casería de los Fontanares mirando al medio día. (Biblioteca de la Real Academia de la Historia, RAH en adelante, Manuscritos, ms. en adelante, 9/5959: fols. 75v-78r).
} 
Pero la Iglesia no sólo iba a transformar los espacios paganos de culto propiamente dichos, sino que también iba a tender, acentuadamente, a ocupar con el culto cristiano los espacios públicos romanos de carácter más laico, llenando así el vacío dejado por el Estado tras la crisis del siglo III. Quirosa García ha querido ver tras esta actitud, además, medidas de protección del patrimonio por parte de la institución eclesiástica:

La sacralización del patrimonio como principal medida de protección: Observamos estas medidas en fechas muy tempranas, como la creación de iglesias y martirae en lugares como el Coliseo, o el auge de las peregrinaciones y, sin duda, la presencia de Papas visionarios que serán quienes empiecen a desarrollarlas (QUIROSA GARCÍA, 2008: pp. 19-20).

Si bien esta vertiente patrimonialista puede ser discutible, sí que es indudable que la consagración de un espacio antes pagano o laico era inherente al concepto de "propiedad" de la Iglesia. Los nuevos templos cristianos, o los reutilizados como tal, quedaban revestidos de su carácter de "casa de Dios", y por tanto bajo administración de la Iglesia, sustrayéndose así al dominio particular o "realengo" según el caso.

En esta línea, la consagración del espacio contaba, incluso, con ritual propio, aunque poco conocido. Caballero Zoreda y Sánchez Santos (1990: p. 434) recapitulan que:

Otras dos anotaciones de RIGHETTI (pp. 1.156 y 1.061 ) inciden en 10 mismo y se relacionan además con otros temas tratados en nuestro texto. El que el obispo escriba el abecedario sobre las bandas de ceniza cruzadas diagonalmente sobre el pavimento de la iglesia, en su consagración, representa para este autor una reminiscencia clásica del augurio que determina los confines del suelo sagrado. Esta escritura, como la lustración, se repite en las paredes de la iglesia y en los dinteles de la puerta de entrada que, como recuerda Righetti, es la proclamación de que "Satanás" ha abandonado el edificio, en su función exorcista.Y, finalmente, la unción con crisma y la oblación de incienso en el centro y en las esquinas de la mesa del altar, en la misma ceremonia, de la que dice que "se consuma como el holocausto antiguo", aunque debe referirse al judaísmo y no propiamente a una costumbre pagana.

\section{CÁSTULO Y LA ERMITA DE SANTA EUFEMIA}

La dinámica descrita no va a ser privativa de la tardo-antigüedad y Alta Edad Media, sino que se va a perpetuar a lo largo de la Edad Moderna, ganando peso su vertiente de ocupación del territorio y perdiéndolo la de desplazamiento de los cultos paganos. Echevarría, al abordar otro aspecto de este proceso, la conversión de mezquitas en iglesias, comienza señalando que:

Al plantearse la idea de "marcar el espacio, iglesias y espacio eclesiástico como reto ideológico", una de las primeras cuestiones que se nos plantean es iqué puede marcar más el espacio que la transformación de los símbolos religiosos del enemigo, en este caso, la de los espacios sagrados musulmanes que se van conquistando al avanzar hacia el sur? Sobre esta transformación del espacio se va a construir la legitimidad política del tipo cuasi-nacionalista que desarrollarán Rodrigo Jiménez de Rada y Lucas de Tuy, a las que se dedican otros estudios de este volumen. Nos referimos sobre todo al reino de Castilla, aunque en algunos momentos pueda aportar ejemplos de otros reinos peninsulares (ECHEVARRÍA, 2003: p. 53).

Más adelante afirma que

A través de la ocupación de mezquitas y su transformación en iglesias, y de la construcción de nuevos lugares de culto, se está efectuando una redefinición del espacio, que es legitimada paralelamente a través de las fuentes escritas, que son las que crean el verdadero sentido de identificación con el pasado previo a la invasión musulmana (ECHEVARRÍA, 2003: p. 60). 
Es bastante probable que el caso de la ermita de Santa Eufemia de Cástulo se ajuste con gran exactitud a esta dinámica. El templo debió consagrarse, en primer lugar, en un momento indeterminado posterior a la Reconquista, con la intención de sacralizar y articular aquel espacio que había permanecido ocupado por el "infiel". Ambrosio de Morales, en el último tercio del siglo XVI, ya nos habla del mismo, poniendo de relieve que debió levantarse con bastante anterioridad a dicha fecha (1575: p. $214)^{5}$.

La legitimación realizada mediante las fuentes escritas cobra cada vez más importancia en el marco de la ocupación de los espacios públicos a medida que avanza la Baja Edad Media y la Alta Edad Moderna, debido a la inexistencia del "otro" (paganos primero y musulmanes después), al que es necesario sustituir, siendo el principal elemento legitimador de esta ocupación del espacio lo recogido sobre el papel en forma de crónicas y narraciones históricas que remiten a la tardo-antigüedad, momento en que tienen su origen estos parámetros teóricos.

Es en esta línea en la que se inscribe la obra del jesuita Jerónimo Román de la Higuera. Nacido en Toledo en el siglo XVI y fallecido en $|6| 1$, redactó, en torno a 1549 , una serie de "cronicones" a los que dio un supuesto origen paleocristiano, atribuyéndolos a autores tales como Flavio Lucio Dextro o Marco Máximo. En ellos presentaba una gran cantidad de datos de carácter hagiográfico, en su mayoría carentes de un respaldo de veracidad, que tendían a aumentar desmesuradamente la cantidad de santos y mártires que habían habitado la Península Ibérica. A su vez, hasta 1868, fecha en la que el académico de la Historia José Godoy Alcántara demostró la falsedad de estas obras, otros autores, tomando como base sus escritos, abundaron en la cuestión, siempre en la línea de la identificación de lugares y poblaciones concretas con los correspondientes episodios martiriológicos, lo que suponía la continuidad en el proceso de cristianización de los espacios públicos que estamos viendo.

En el caso de Cástulo, en segundo lugar y a partir de la denominación que comienza a recibir el terreno ocupado por el yacimiento arqueológico desde la Edad Media -Cazlona-, Román de la Higuera estableció una correspondencia directa entre la ciudad ibero-romana y Calcedonia -situada, en realidad, en el Mediterráneo oriental-, de cuya correspondencia se deducía, de forma evidente, que era en Cástulo donde se había producido el martirio y muerte de Santa Eufemia. El fervor popular y el mecanismo de cristianización de los espacios públicos implementado por la Iglesia desde muchos siglos atrás hicieron el resto, y así, ya entrado el siglo XVII, volvía a tomar valor una pequeña ermita con la advocación de la referida santa, que se levantaba sobre la antigua ciudad.

En este tipo de procesos era muy habitual apoyarse en la presencia de materiales constructivos romanos reutilizados en los edificios cristianos, especialmente determinados elementos rituales (aras) y funerarios, que quedaban vistos y que contribuían, de esta manera, a aumentar la sensación de continuidad de los inmuebles con el mundo clásico y, por tanto, con el episodio hagiográfico en cuestión. En esta línea, Salas Álvarez pone de relieve también la existencia de cierto carácter museístico en este tipo de espacios:

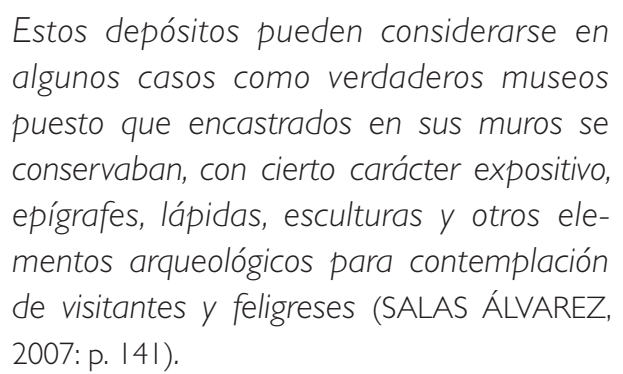

Aunque la ermita de Santa Eufemia no se conserva en alzado, podemos afirmar que la reutilización de materiales debió ser especial-

5 En una pared de la Iglesia de Santa Eufemia, que esta en el sitio de Cazlona, está una piedra con una figura de mujer de medio relieve, que con el un dedo señala en alto, y con el de la otra mano señala hacia abajo. Con casi total probabilidad debe referirse al "Epitafio de Crisis" (CIL II, 3.289). 
mente acentuada, no sólo debido al criterio enunciado, sino también a otro meramente utilitarista, dada su abundancia en el entorno próximo. Este aspecto queda también confirmado por las afirmaciones Antonio Ponz (PONZ, 179|: p. 154) y de Pérez Bayer:

En este colladito de la izquierda hay una ermita dedicada a Santa Eufemia, Virgen y Mártir, bastantemente capaz con su atrio y una pequeña hospedería. Toda esta ermita, por dentro y por fuera, el atrio y la hospedería, está encastrado de inscripciones romanas, y en la circunferencia de la ermita hay una selva de trozos de columnas y capiteles, festones y volutas de varios órdenes, lisas, estriadas, de varios gruesos y tamaños (RAH, ms. 9/5498: fol. 58r).

Durante la Edad Media, el cuidado de estos edificios era realizado, como su propio nombre indica, por la figura del ermitaño, individuo que residía en ellos llevando una vida ascética y atendiendo a los cultos. Pero la creciente burocratización experimentada por la Iglesia va a producir una evolución de esta forma de gestión, quedando estos inmuebles, en la mayoría de los casos, adscritos a una determinada parroquia, institución monástica u otros tipos de entidades piadosas de carácter seglar, como podían ser patronatos, capellanías o hermandades.

En el caso de Linares, la gestión de las ermitas del término -y por tanto la de Santa Eufemia- estaba encomendada a la hermandad de la Vera Cruz de la villa. Fundada en torno a 1554 en el convento de San Francisco, sus "ordenanzas y constituciones" fueron aprobadas por el Obispado de la Diócesis en I558. A principios del siglo XVII, la hermandad debió trasladarse a la parroquial de Santa María, donde se encontraba ya establecida desde el año 1633.

Respecto a su organización, sabemos que:

La cofradía estaba regida por un prioste, priostre o gobernador, que en 1647 era Bartolomé Sánchez de Arista, apellido este muy linarense: dos alcaldes, un alférez mayor, un notario, que solía ser el escribano del número de la villa, y seis diputados o hermanos mayores de las escuadras que componían la cofradía. Todos ellos eran los llamados oficiales y los únicos que tenían voto en los cabildos. A los cabildos asistía el prior,-como se llamaba en el reino de Jaén a los párrocos-, en calidad de presidente, que solía delegar en un cura o beneficiado de Santa María. También las "escuadras" solían tener un contador, un tesorero, e incluso dos diputados u oficiales. Los cofrades o hermanos, por pertenecer a una escuadra se llamaban escuadrantes (ORTEGA Y SAGRISTA, 1997: p. 36).

En cuanto a estas escuadras, habría que señalar que eran cinco y que cada una de ellas ...tenía a su cargo una "insignia" o imagen que sacaban en procesión. Estas escuadras eran anejas o agregadas a la cofradía y tenían su régimen particular, con sus fondos propios y cierta autonomía dentro de la congregación (ORTEGAY SAGRISTA, 1997: p. 37).

De estas escuadras que integraban la hermandad, la que nos interesa, de cara al objeto de este trabajo, es la titulada "de la Madre de Dios de los Dolores" o de "Nuestra Señora de los Dolores". Se trataba de ... una de las primitivas de la cofradía de la Santa Vera Cruz. Pero vino en decadencia y se extinguió, quedando sólo un hermano, llamado Simón Marín, que la fundó de nuevo el año 1756... (ORTEGA Y SAGRISTA, 1997: p. 37). Tenía ...entre sus fines esenciales, como dice el cronista Don Juan Sánchez Caballero, la fundación y sostenimiento de varias ermitas extramuros de esta villa... (ORTEGA Y SAGRISTA, 1997: p. 43).

Es probable que esta institución piadosa fuese uno de los agentes implicados, en el siglo XVII, en la revitalización de la ermita de Santa Eufemia, promovida en última instancia por los datos contenidos en la obra de Román de la Higuera, que debieron llegar a conocimiento de los hermanos de la misma. A su vez, dada la funcionalidad de esta "escuadra", no sólo habría sido uno de los agentes en el proceso, sino también la institución responsable del mantenimiento de la ermita, tanto materialmente como respecto a los correspondientes cultos que habían de celebrarse en la misma. 


\section{LA EXTRACCIÓN DE LAS COLUM- NAS DEL PÓRTICO DE SANTA EUFEMIA 6}

Dada la situación que presentaba la escuadra de la Madre de Dios a mediados del siglo XVIII, previamente a la refundación llevada a cabo por Simón Marín, lo más probable es que la ermita se encontrase al menos desatendida, ya que la institución encargada de su mantenimiento se hallaba prácticamente extinguida.

Esta era la situación general del inmueble y sus aledaños cuando fue promulgado el Real Decreto de 14 de julio de 1753. En el caso de Linares, éste fue remitido a Carlos Lanci, intendente de minas del distrito, que en cumplimiento del mismo comenzó la recogida de elementos arqueológicos en Cástulo. En este marco, llamaron especialmente su atención dos columnas de jaspe que sostenían el pórtico de acceso a la ermita, por lo que, amparándose en el estado de abandono que ésta debía presentar ya, procedió a su desmontaje y traslado, inicialmente a la Casa de la Moneda de Linares y, posteriormente, a la Real Casa Geográfica y Gabinete de Historia Natural, en Madrid. Esta acción provocó un inmediato conflicto entre la autoridad eclesiástica y el intendente, tras el que subyace el antagonismo que comenzaba a generarse entre la idea patrimonial desarrollada por la Iglesia durante siglos y las nuevas ideas ilustradas respecto al mismo, con sus consecuentes experiencias tutelares.

Tras la extracción de las columnas, el 26 de febrero de 1754, José de Vargas acudía ante el correspondiente notario apostólico para otorgar un poder al procurador Francisco José Rodríguez e iniciar el proceso judicial. Vargas se presentaba en dicho documento como administrador interino de la cofradía de la Madre de Dios, lo que viene a sustentar los datos aportados por Ortega y Sagrista acerca de la decadencia de esta escuadra, que debido a la falta de hermanos habría sido puesta bajo el control del susodicho.

Las funciones de la hermandad estarían mermadas, por lo que la ermita de Santa Eufemia debía presentar, en ese momento, cierto estado de abandono. Al otorgar su poder, Vargas declaraba que:

...por cuanto la ermita de Santa Eufemia, que esta en el sitio de la Muela, es una de las agrupadas a dicha cofradía, y en ella se ha celebrado el santo sacrificio de la misa y diferentes funciones a que concurre la parroquia. Y aunque esta se hallaba con unas lumbres menos, y teniendo la cofradía comprados los materiales para su edificación, ha llegado a noticia del otorgante cómo, por diferentes personas, se ha deshecho el pórtico de ella, quitando y trayéndose dos columnas de jaspón que lo sustentan, y por lo costoso que era a la dicha cofradía el hacer dicho pórtico y otras razones, otorgó por la presente que da su poder cumplido, el que de derecho se requiere y es necesario a Don Francisco Manuel Rodríguez, procurador eclesiástico en la audiencia de la ciudad de Jaén, para que en mi nombre y representando a mi persona, pueda parecer y parezca ante el señor gobernador, provisor y vicario general de este obispado, y demás señores jueces que con derecho pueda y haciendo relación de lo referido, se querelle contra los que han tomado y traídose las columnas y demás materiales, deshaciendo dicho pórtico de autoridad propia, con menosprecio de la inmunidad eclesiástica y que esta quede inteligenciada, y dicha cofradía de sus materiales hasta conseguirlo... (AML. Leg. 2570, exp. 3, fol. I r).

Por su parte, el procurador presentó la correspondiente querella, que completa la visión que sobre la extracción de las columnas quería darse, acusando a

6 La mayor parte de los datos que aportaremos a continuación acerca de la ermita de Santa Eufemia proceden de un pleito conservado en el Archivo Municipal de Linares, entablado entre el representante legal de la "escuadra" de la Madre de Dios de los Dolores y Carlos Lanci, intendente de minas del distrito, debido a la extracción de dos columnas que formaban parte del pórtico de la ermita de Santa Eufemia. El expediente consta de 22 folios en papel, redactado en humanística cursiva por el escribano Francisco José Polo de Cozar en 1754. 
...Don Carlos Lanzi, intendente de minas y plomos de dicha villa y digo que con ocasión de hallarse como se hallaba la expresada ermita algo deteriorada, y sirviéndole de entibo al pórtico de ella dos columnas de jaspón, que recibían las maderas de dicho pórtico, de su propia autoridad las tomó y aprovechó en sus propios usos el interesado Carlos Lanzi, esto con poco temor de Dios y menosprecio de la justicia que VS administra, abriéndose de aquí no sólo el extravío de dichas columnas, que eran no de corta consideración, sino es también el perjuicio del hundimiento, según y en la conformidad que a pedimento de mi parte se ha reconocido y declarado por perito en fuerza de despacho de VS que ganó separadamente, y no siendo justo se tolere este agravio y siendo en ofensa de dicho lugar sagrado, pues en él se celebra el santo sacrificio de la misa y habiéndose hecho acreedor dicho Don Carlos y demás culpados de las mayores y más graves penas por derecho establecidas, para que se le impongan y sirvan de escarmiento, y a otros de ejemplo dándose a incidencia por VS provisoría, no sólo para la restitución de dichas columnas, sino es también para que, indemnizado, quede subsanado el daño que con haberlas movido se ocasionó a dicha ermita (AML. Leg. 2570, exp. 3, fol. 2 r-v).

Visto el planteamiento de las acusaciones, quedan bastante claras cuáles iban a ser las líneas a seguir por parte de los demandantes a lo largo del proceso:

- Abundar en que Lanci había sustraído las columnas por iniciativa e interés propio, soslayando la posibilidad de que, como funcionario real que era, contase con órdenes para ello.

- Refuerzo del carácter de lugar de culto cristiano de la ermita, muy vinculado al concepto patrimonial de la Iglesia, como hemos visto en epígrafes anteriores.

- Minoración del estado de abandono en que podía encontrarse el inmueble, que, por tanto, seguía siendo un lugar de culto en activo y propiedad de la Iglesia. En este caso, los desperfectos evidentes, tales como la falta de las mencionadas "lumbres", intentaban ser suavizados con la afirmación de que serían reparados inminentemente.

Planteadas estas bases comenzaron a ser llamados distintos testigos en cuyas declaraciones encontramos nuevos datos, tanto acerca del estado de conservación del edificio, como de la actuación de Lanci respecto a las columnas del pórtico. El primero de ellos fue Miguel Suárez Carrillo, que afirmó que:

... es cierto que habrá tiempo de dos meses, a corta diferencia, que Don Carlos Lanci, intendente de minas de esta villa, le mandó a este testigo que reconociese las columnas de jaspón que estaban manteniendo el pórtico de la ermita de Santa Eufemia, que está al sitio de la Muela de este término, si estaban muy dentro de la tierra, las que habiendo reconocido el testigo con todo cuidado halló que la una estaba dentro de ella como media vara, y la otra una tercia, y que estas se hallaban en proporción de haber recibido las maderas del pórtico de dicha ermita en el tiempo que no estaba hundido y que asimismo reconociese el testigo la calidad de la piedra de dichas columnas, cuya diligencia hecha halló que eran de dicha piedra jaspón, lo que habiéndolo noticiado al referido Don Carlos Lanzi, mandó quitarlas de este sitio y que se condujeran, como las condujo José Picazo, carretillero, con otros mozos, y que hoy se hallan dichas columnas en las casas que llaman de la moneda de esta dicha villa, las cuales vio el testigo cargar en el sitio y postigo de dicha ermita de Santa Eufemia... (AML. Leg. 2570, exp. 3, fol. 4 r).

Queda claro que el objetivo de este testimonio era, evidentemente, el de presentar a Lanci como el inductor de la extracción de las columnas, si bien los detalles aportados por Suárez, en cuanto al estado de la ermita y los propios soportes, parecen avalar el estado de abandono de la misma. En primer lugar, sabemos - por afirmaciones anteriores recogidas en la propia denuncia- que el santuario presentaba 
varias "lumbres" en mal estado. El Diccionario de Autoridades de 1734 establece la correspondencia entre el término "lumbre" con el de "lumbrera", definiendo este último como ...la ventana o claraboya que comúnmente se construye, en lo alto de los techos o paredes, para dar luz a las casas o lugares subterráneos (RAE. A., I734: p. 438) ${ }^{7}$. De aquí se puede inferir que el sistema de iluminación superior de la iglesia -aunque no podamos precisar si se abría directamente en la cubierta o en la zona alta de los muros- se encontraba en mal estado de conservación, de lo que se deduce que las techumbres también debían estarlo. Por su parte, al referirse a las columnas, el testigo refiere, claramente, que éstas sostuvieron el pórtico en su momento, aunque últimamente no lo hacían al estar éste hundido. Esta versión nos parece bastante más creible que la aportada por el administrador de la "escuadra" y su procurador, ya que es muy improbable que, a mediados del siglo $X V I I I$, un funcionario real hubiese ordenado el desmontaje completo del pórtico de un edificio religioso con el objeto de extraer dos columnas, algo que sería más comprensible si éstas, debido al estado de ruina del inmueble, hubiesen perdido su función previamente.

El hecho de que las longitudes de los segmentos soterrados de ambos soportes fuesen distintos entre sí ( I/2 vara $=41,79 \mathrm{~cm}$. y I/3 de vara $=27^{\prime} 86 \mathrm{~cm}$. aproximadamente), teniendo en cuenta que sus remates superiores debían alcanzar la misma altura, nos podría llevar a pensar que se trataba de elementos de distinto módulo. Obviamente eran dos piezas de acarreo, pero nos inclinamos a pensar que esta diferencia de medidas podría deberse a que se trataba de dos fragmentos incompletos de una misma procedencia.

Finalmente, el testimonio culminaba en la línea que hemos indicado al comenzar su análisis, señalando que:
.... [en la ermita] se han celebrado misas y fiestas a las que ha concurrido la parroquia, la cual tiene obligación a cumplir en dicha ermita algunas dotaciones, cuyo cumplimiento ha oído decir el testigo esta mandado suspender hasta la reparación de dicha ermita, que es cuanto puede decir en razón de lo que ha sido preguntado... (AML. Leg. 2570, exp. 3, fol. 4 r).

A continuación fue llamado a declarar Martín Garrido, arriero responsable del traslado, que se limitó a relatar cómo se procedió a la carga y transporte hasta la casa de la moneda de Linares, si bien, siguiendo el interrogatorio predeterminado, finalizó su exposición aseverando que había ... oído decir el testigo cómo en dicha ermita se ha celebrado el santo sacrificio y fiestas a que ha concurrido la parroquia, la que está obligada a cumplir en ella algunas dotaciones... (AML. Leg. 2570, exp. 3, fol. 4 v).

Idéntica estructura ofrecía el testimonio de Pedro Pablo Delgado (AML. Leg. 2570, exp. 3, fol. $4 \mathrm{v}-5 \mathrm{r}$ ), uno de los peones que participó en la extracción, que no aporta información relevante alguna, y el de José Picazo, propietario de las carretas en que se hizo el traslado (AML. Leg. 2570, exp. 3, fol. 6 v).

Mayor interés presenta, sin duda, la declaración de Manuel de la Cueva, que testificó en calidad de clérigo de menores y sochantre de la parroquial de Santa María, afirmando que:

...con motivo de haber ido a un entierro, a las casas de la moneda de esta villa, vio en dichas casas dos columnas, las que el testigo conoció eran del pórtico de Santa Eufemia, y para más satisfacerse lo preguntó, y le dijeron que ellas eran, y que de orden de Don Carlos Lanzi las habían llevado a dicha casa, y asimismo sabe el testigo cómo, en la ermita de Santa Eufemia, se ha celebrado

\footnotetext{
7 RAE. A. (1734): 438. El Vocabulario básico de Arquitectura de José Ramón Paniagua (1978), por su parte, indica que el término "lumbre" se ajusta al término "luz", que hace referencia a Cada uno de los vanos que en un edificio proporcionan la iluminación de sus interiores. Por otro lado, señala que el término "lumbrera" hace referencia a la Abertura, caño o tronera, generalmente vidriada, dispuesta en el techo o cubierta de una estancia, para proporcionar luz y ventilación desde el exterior, o a la Ventana en saledizo, generalmente por la elevación de una parte del plano inclinado de la vertiente de un tejado, acepción con la que coincide también el Diccionario de términos de Arte y elementos de Arqueología, Heráldica y Numismática de Guillermo Fatás y Gonzálo Borrás (1988).
} 
el Santo Sacrificio de la misa rezada, en memoria del señor San Amando. Obispo que se dice fue de la ciudad de Cast[ulo] hoy destruida, cuyas memorias han esta[do] cumpliéndose hasta el año pasado de mil setecientos treinta y cinco en la dicha ermita, sin embargo de tener en aquel tiempo dos lumbreras arruinadas, y así para repararlas y ponerla con decencia mandaron los señores visitadores que se suspendieran las memorias y fiestas que había fundadas en todas las ermitas de la comprensión de esta parroquia y que no continuaran hasta que estuvieran enteramente reparadas... (AML. Leg. 2570, exp. 3, fol. 5 r- 5 v).

Este testimonio, además de confirmarnos que, efectivamente, una vez extraídas las columnas fueron depositadas en la Casa de la Moneda de Linares, nos aporta datos adicionales acerca del estado de abandono en que se encontraba la ermita, recogiendo que los primeros problemas en sus cubiertas ya se habían producido en 1735, motivo por el cual que los visitadores del Obispado habían procedido a clausurarla. En este estado permaneció durante casi veinte años, sin que se llevasen a cabo las necesarias reparaciones. Idénticos datos aporta el testimonio de Pedro Sánchez, presbítero y sacristán de Santa María, que también asistió al mismo entierro en las Casas de la Moneda (AML. Leg. 2570, exp. 3, fol. 5 v- 6 r).

\section{HISTORIA DE UN ABANDONO}

Recapitulando, ninguno de los testimonios avalaba totalmente las líneas planteadas en la demanda. Quedaba claro que Lanci había ordenado la extracción de las columnas, pero ningún dato se aportaba acerca de los motivos que le habían impulsado a ello. Sí quedaba claro que en la ermita se habían oficiado misas y administrado sacramentos, pero todos los actos de culto habían sido suspendidos hacía algo más de 20 años (1735), desde que el edificio fuera cerrado al hacerse patentes los problemas estructurales de su fábrica. La cronología de la degradación del inmueble, por tanto, en base a los datos proporcionados por los testimonios, puede sintetizarse en tres fases:
- Una anterior a 1735, caracterizada por la aparición de problemas en las cubiertas, lo que obligó a su clausura.

- Una comprendida entre 1735 y |754, caracterizada por el derrumbamiento del pórtico y, seguramente -debido a la ausencia de labores de mantenimiento-, por la agudización de los problemas en la techumbre.

- Otra focalizada en 1754, cuando tuvo lugar la extracción de las columnas.

Pero, para apoyar sus pretensiones, José de Vargas y su procurador no sólo presentaron los testimonios ya vistos, sino que también adjuntaron documentación escrita al proceso. Destaca entre ella el traslado de un reconocimiento del inmueble realizado por Juan Cañadas, fiel veedor de edificios del cabildo municipal, en el que se afirmaba que:

....reconoció el declarante con todo cuidado y diligencia, y hallado en ella ser necesarios los reparos y obras siguientes:

Primeramente, habiendo visto y reconocido la iglesia de la ermita de Santa Eufemia que está en el término de esta villa y sitio de la Muela ha hallado que la fábrica de ella es de sillería de mucha estimación, pues no hay en esta villa ermita de tanta fortificación y su anchura es de diez varas poco más o menos y su latitud de veinte y seis, cuyas paredes o muros no necesitan de reparado alguno en muchos siglos, pero reconocido el tejado se ha hallado que para distintas lumbres que tiene vendidas y otros reparos que hay que hacer se necesita de novecientos reales de vellón.

Y asimismo el declarante, habiendo reconocido el pórtico de dicha ermita, que este estaba para resguardo de las puertas principales, que están al temporal, y que siempre es preciso volverlo a reedificar, porque de no, se perjudica a las puertas y pared de la portada de dicha ermita. Ha hallado la falta de dos columnas de jaspón, que recibían las maderas de dicho pórtico, por cuya falta será el gasto mucho más crecido, pues siendo dichas columnas que habrá tiempo de un 
año que vio el declarante, para el mismo fin, en aquel dicho sitio, de grande estimación, por tener como tienen de mensura la una dos varas y tres cuartas y la otra de dos varas $y$ tercia, que ceñida circunferencia comprende dos varas y media tercia, y de diámetro dos tercias de grueso, que según reconoció en el tiempo que estaban en aquel sitio y vio el declarante, tendrían según su inteligencia cincuenta ducados de valor, y si se hubieran de conducir desde el sitio de donde se presume se edificaron, ni con dos mil reales se podrían costear, cuya costa de hacer dicho pórtico tendrá de gasto quinientos reales de vellón sin las columnas.

Asimismo ha reconocido que para hacer unas puertas para dicha ermita tendrá una costa de cuatrocientos y cincuenta reales.

Y con dichos reparos se podrá celebrar el santo sacrificio de la misa, y así lo declaró según su leal saber y entender, bajo el juramento que tiene hecho en que se afirmó y dijo ser de edad de treinta y cinco años (AML. Leg. 2570, exp. 3, fol. 8 r- 9 r).

Este traslado termina de configurar la caracterización que del edificio podemos hacer en estos momentos de abandono. Se trataba de un edificio de planta de cajón, de 8'36 m. de anchura por 21'73 m. de longitud aproximadamente, levantado con sillería -probablemente reutilizada de edificios colindantes más antiguos- y que contaba con un único acceso, orientado, probablemente hacia el sur. Como ya habíamos visto, las cubiertas se encontraban en mal estado, pero además, según el reconocimiento, era necesario hacerle unas puertas, lo que implica que, o bien las había perdido o bien se encontraban en un avanzado estado de deterioro. Éste es uno de los aspectos de mayor importancia, puesto que, si el acceso al interior del edificio resultaba franco para cualquier individuo, es bastante probable que hubiera sido utilizado como cobijo de animales y pastores -dado el estado de abandono al que se había visto sometido durante veinte años y la función de dehesa que había ejercido el área de Cástulo-, lo que habría contribuido, en gran medida, a aumentar su deterioro.
El reconocimiento, con respecto a las columnas, también nos permite advertir algunos datos adicionales. Las longitudes de cada una de ellas eran de 2,30 y I,95 m. aproximadamente; tenían un diámetro, con mayor o menor margen de error, de 0'56 m. y mostraban un arco de circunferencia de en torno a 1,81 m. La combinación de estas medidas con las de sus segmentos soterrados, aportadas por Miguel Suárez Carrillo, nos permite acercarnos a la altura que debía alcanzar el pórtico. Habría que señalar que se trata, tan sólo, de una aproximación, ya que ninguno de los datos aportados parece tener en cuenta el desnivel del suelo, al que se puede atribuir la diferencia de cota resultante entre ambos soportes. Así, restando a la altura global de los mismos la de sus cimientos, obtendremos que uno de ellos alcanzaría una altura de 1,88 m. aproximadamente, mientras que el otro llegaría, tan sólo, a la de 1,67 m. El pórtico, en definitiva, debía situarse a una distancia intermedia entre ambas medidas.

\section{EL ALEGATO DE CARLOS LANCI}

Tras la presentación de estos testimonios e informes, el Provisor del Arzobispado, que actuaba como juez en la causa, condenó a Carlos Lanci a restituir - de inmediato- las columnas a su lugar de origen, dejando a su vez la puerta abierta a otras penas de carácter pecuniario. Esta sentencia le fue notificada al interesado, que hasta ese momento había sido mantenido totalmente al margen del proceso que contra él se llevaba. Pero Lanci, individuo dotado de una sólida formación jurídica y que en su faceta de intendente de minas tenía atribuciones al respecto, sabía que el proceso ejecutado contra él era muy irregular, entre otras cosas por el mero hecho de no habérsele notificado las diligencias iniciadas. Ante esta situación, apoderó como procurador a Juan Montero y Morales, que presentó el correspondiente memorial para solicitar un traslado de los autos y, de este modo, iniciar la defensa de su cliente. En el mismo, adelantaba cómo la extracción de las columnas se había hecho por 
...el particular encargo de recoger monumentos de la antigüedad para remitirlos a la casa de Geografía de la corte de Madrid, en virtud de especial orden de SM comunicada por el excelentísimo señor Marqués de La Ensenada... (AML. Leg. 2570, exp. 3, fol. | $4 r-15 v)$.

Por supuesto, mientras esto ocurría, Lanci hacía caso omiso de la orden de devolver las columnas a su costa, entre otras cosas porque aún no consideraba las diligencias resueltas. Así, la presentación del memorial de su procurador coincidía con otro del que actuaba en nombre de la parte contraria. El resultado de ello fue la recepción, por parte de Lanci, de una nueva notificación en la que se le instaba a cumplir con lo ordenado por el tribunal ...so pena de excomunión mayor, citación para su declaración y cincuenta ducados de multa, en que desde luego le damos por condenado lo contrario haciendo... (AML. Leg. 2570, exp. 3, fol. |4r-15v).

Como reacción -en el mismo momento de recibir la amenazante notificación-, requería del mismo escribano que levantase testimonio de lo que tenía que poner de relieve. Realizó entonces un alegato, de varios folios de extensión, en el que fundamentaba la legalidad de la extracción -aportando detalles concretos sobre el estado de la ermita- y que quedó integrado en los autos del proceso. Finalmente, el caso debió ser sobreseído a raíz de dicha defensa, ya que el expediente finaliza aquí. No obstante, lo que nos interesa es el contenido del alegato, que completa la serie de datos de que disponemos sobre el conflicto generado.

Lanci comenzaba arremetiendo, directamente, contra la existencia de la propia ermita, considerando sus restos como simples ruinas y declarando

... ser falsa la existencia que se le ha supuesto de la ermita y pórtico que refieren y serlo igualmente que le perteneciese la propiedad ni el dominio de los dos trozos de columna reclamados con este pretexto con el intruso administrador... (AML. Leg. 2570, exp. 3, fol. $17 v)$.
Sin duda, debía ser consciente de que esta rotunda afirmación no iba a ser considerada por el tribunal sin más, pero plantear dudas sobre la función del edificio era una buena base para llegar, finalmente, a conceptualizar las columnas -dada, igualmente, la inexistencia del pórtico, derrumbado hacía algún tiempo- como elementos totalmente ajenos a la jurisdicción eclesiástica. Pero antes de abundar en esta cuestión, proseguía argumentando que la extracción de los soportes había sido una acción emanada de la autoridad real y ejecutada en un espacio público, que no era otro que la ciudad de Cástulo:

...por cuanto el hecho cierto, constante y público sobre dicho asunto es que dichos dos trozos de columna que dicho señor hizo conducir a esta villa, del sitio donde fue la antigua Cástulo, en virtud de las órdenes de SM proceden y son de las ruinas de aquella antigua y memorable colonia cuyos vestigios pertenecen a la regalía y supremo dominio del príncipe... (AML. Leg. 2570, exp. 3 , fol. 17 v).

Hecha esta puntualización, continuaba con el argumento inicial, agregando que:

... [las columnas] jamás sirvieron al cuerpo del edificio de la referida ermita, ni para su fortaleza ni para su ornato, interior ni exterior, y que de tiempo a esta parte se han hallado dichos dos trozos de columna separados de la dicha ermita y edificio, que según parece hubo y existió, habiendo quedado en aquel campo y en la distancia de más de quince pies del cuerpo de lo que se supone fue ermita, con la misma desestimación que tienen otras muchas piedras y fragmentos de aquellas ruinas... (AML. Leg. 2570, exp. 3 , fol. 17 v).

Terminaba enlazando ambos argumentos, de manera que quedaba ratificada la propiedad real del espacio y los elementos antrópicos contenidos en el mismo, en tanto su conceptualización como ámbito público:

... en que conservándose el supremo dominio de la regalía, se hace promiscuo el derecho común, sin poder prescribir ni enagenar su 
propiedad a menos que no conste de donación regia u otro género de enajenación, y aun en tal caso, cesando el uso y quedando en el antiguo ser vino a suprimir el derecho temporal de suerte que aun cuando dichas piezas hubiesen servido para un pórtico $u$ cobertizo que se había formado a la entrada de dicha ermita, habiéndose hallado quebrado y destrozado por aquellos derrumbaderos por tantos años y no en pie como supone falsamente el pedimento, cesó la cualidad y pertenencia pretendida a favor de la ermita... (AML. Leg. 2570, exp. 3, fol. 18 r).

Estas afirmaciones sitúan a Lanci en el seno del regalismo ilustrado, corriente sostenida por juristas que consideraban que, si la Monarquía había luchado por la implantación de la Contrarreforma después de Trento, se había establecido un patronato universal de ésta sobre la Iglesia española, que sólo debía tener la primacía en los asuntos espirituales, considerando que las prebendas, privilegios y propiedades eclesiásticas eran, en realidad, concesiones reales, de manera que existían supuestos en los que podían volver a manos del monarca. En su origen, esta vertiente del regalismo estuvo vinculada a ideas jansenistas, centradas en el debate en torno a la legitimidad, o no, de que la Iglesia poseyese bienes terrenales:

¿La Iglesia tiene que poseer? ¿Todo lo terreno pertenece al Estado? ¿Cuál es el límite de las dos potestades? Según se dé una respuesta sobre qué es la lglesia, ¿comunidad visible o comunidad espiritual?, habrá una concepción de la misma vida, en el tiempo, de la comunidad de creyentes...

...cuando los reyes católicos colaboran e implantan la reforma (España, Austria, Francia...) la escuela regalista tuvo su lógica. Los que implantan o ayudan a implantarla ¿no tienen derecho a intervenir en la vida de la Iglesia? ¿No son ellos los que deben ser los portadores de lo eclesiástico en lo temporal? La intervención regalista (sin llegar a cisma) podría suponer un control de la Iglesia en su desarrollo institucional. Amortizacióndesamortización; Regalismo-reserva; Fuero competente-control de todos los tribunales;
Fin de los bienes- los bienes asunto terreno, etc.; son puntos que los juristas-canonistas tienen que ir clarificando. La lucha de este siglo radica en el intento de clarificar hasta dónde llega cada jurisdicción en los asuntos mixtos. (BENLLOHC POVEDA, 1984: p. 303).

En esta línea, podemos considerar que, además, el conflicto por las columnas se da en el momento de máximo apogeo de la cuestión regalista. Esto se debe a que el origen de la misma, en los términos mencionados, se situaba a finales del siglo XVII, abarcando toda la primera mitad de la siguiente centuria, en la que se dan los concordatos de 1717 y 1737 , que, no obstante, no satisficieron a ninguna de las partes, ni a la Monarquía ni al Papado. En esta situación, tras una serie de negociaciones dirigidas personalmente por el Marqués de la Ensenada, el I I de enero de 1753, se firmaba un nuevo concordato que finalmente reconocía el concepto de patronato universal de la monarquía sobre la iglesia y que fue muy elogiado por destacadas figuras del regalismo, como Gregorio Mayans. Esta era la base legal y argumental sobre la que Lanci sostenía la legitimidad de la extracción de las columnas, en el marco de la experiencia tutelar iniciada con el Real Decreto de 14 de julio de 1753.

Aportaba, a continuación, una serie de datos concretos que avalaban los aspectos reseñados sobre el edificio. Así, venía a confirmar el uso que se le venía dando como lugar de cobijo de ganado y pastores:

...con superior razón cuando esta se halla de algunos años a esta parte que solo sirven sus paredones de albergue de animales inmundos y otros ganados para diversos usos profanos indecentes a vista de los priores de esta villa y de los supuestos administradores que en ello deberían poner mayor cuidado que el que ahora afectan en su pretensión menos fundada e importante y en oposición de la causa pública de las órdenes de SM, tanto mas que dicha ermita se halla sin esperanza de reedificación, como lo acreditan los decretos de los ilustrísimos señores obispos y sus visitadores... (AML. Leg. 2570, exp. 3, fol. 18 r). 
Tras ello, arremetía contra la incompetencia de los administradores eclesiásticos, a los que acusaba no ya de no ser capaces de llevar a cabo la reconstrucción del edificio, sino ni tan siquiera de aprovechar los materiales constructivos del mismo. Este argumento sería empleado para reforzar la idea de que la Iglesia tenía abandonado el inmueble, por lo que procedía su vuelta -y la del espacio que ocupaba- a la jurisdicción civil, citando incluso el ejemplo de alguna otra ermita del término que, al parecer, había sido desmantelada por los habitantes de Linares para la reutilización de sus materiales:

...ni se ha tratado de aprovechar el material de piedra que quedó de sus ruinas, por no ser de utilidad alguna en aquel sitio y de mayor coste que su importe el conducirlo a esta villa o a otras, donde pudiera servir, de que procede con evidencia el abandono de aquel inútil y no estimable material y haber salido del dominio eclesiástico todo lo que le pudo pertenecer, quedando secularizado y profano, así como en estos últimos años por los mismos motivos y con las agravantes circunstancias de no hallarse en despoblado, si pero a la misma salida de esta villa lo quedaron las piedras de la ermita de San Andrés y no solo las separadas y desprendidas del cuerpo de la ermita, que sin duda pertenecen al uso común y al dominio universal del monarca, pero también las que habían servido al mismo cuerpo de la capilla y las aprovecharon comúnmente los vecinos de esta villa sin reparo de los administradores... (AML. Leg. 2570, exp. 3, fol. 18 v).

A continuación, ponía de relieve la falta de valor sustentante y estructural de las columnas, por lo que consideraba que el oratorio no se había visto perjudicado con la extracción:

en cuyo término los dos trozos de columna carecen de la cualidad necesaria para el fundamento de la pretensión del llamado administrador de la dicha ermita, y no pueden constituir objeto atributivo de la jurisdicción eclesiástica, tanto mas por este esencial motivo, cuanto no teniendo valor alguno intrínseco en el sitio y estado en que se hallaban, no es acomodable el concepto de injuria y despojo de bono ecclesi[a]e con total deficiencia de sujeto y cualidades... (AML. Leg. 2570, exp. 3, fol. 19 r).

A este argumento contraponía el del valor que cobraban los soportes como elementos patrimoniales:

...cuando por el contrario es visible por su materia, proporción y disposición que indican ser dichos trozos de columnas uno de los monumentos notables de Cástulo Gentil, pertenecientes a la regalía de SM cuyo atributo produce privativa jurisdicción a la real de sus ministros seculares, sin que la eclesiástica en puntos de regalía pueda mezclarse ni perturbarla aun en los casos controvertidos con comunidades y personas eclesiásticas, en cuya consideración debiera sosegar el empeño del llamado administrador sobre la reivindicación que intentan en su pedimento de dichos dos trozos de columna, sin otra utilidad que la contravenía a lo mandado formalmente por SM, que con los mas importantes motivos y en lustre y honor de la nación promueve por estos medios y otros la loable tarea de la erudición española y sus nuevas academias y desairar a los ministros de SM que fielmente conspiran en debida obediencia de sus órdenes... (AML. Leg. 2570, exp. 3, fol. 19 r).

Lanci terminaba su alegato amonestando a la parte contraria y exigiendo la inhibición del juez eclesiástico y, por tanto, la nulidad del proceso, si bien se ofrecía a pagar dos columnas nuevas para sustituir a las extraídas, bajo la condición de que se reedificase la ermita. El auto termina aquí, con la notificación de este alegato a las partes y una amonestación al escribano por haber dado a Lanci testimonio del mismo, cuando, según el juez, tan sólo debía haber notificado la sentencia. Todo ello nos lleva a pensar que los fundamentos legales que el acusado trajo a colación, unidos a las órdenes reales con que contaba, obligaron al juez eclesiástico a inhibirse, anulándose tanto la causa como la sentencia a que había dado lugar. A partir de entonces, las columnas del pórtico de la ermita de Santa Eufemia iniciarían su periplo hacia Madrid. 


\section{LAS COLUMNAS Y LA CAÍDA DE ENSENADA}

Tan sólo meses después de la fecha del último documento incluido en el proceso estudiado, el 20 de julio de 1754, se producía la detención del Marqués de la Ensenada como resulta de una conspiración cortesana instigada por el embajador inglés Benjamin Keene ${ }^{8}$. Su sucesor fue Ricardo Wall, aventurero de origen irlandés que había sido pieza clave en la conjura y que, tras el destierro de su predecesor, comenzó una política sistemática de destitución de todos los "ensenadistas" que ocupaban cargos en la administración, procediendo también a la congelación de todas las reformas e iniciativas políticas llevadas a cabo por el Marqués.

Estos hechos afectaron también a la recién creada Real Casa Geográfica y Gabinete de Historia Natural, siendo una de sus primeras consecuencias la "dimisión" de Antonio de Ulloa al frente de la misma, que ...sin duda se vio afectado por el cese fulminante de Ensenada, tras la muerte de Carvajal y su sustitución por el irlandés Ricardo Wall (PUIG-SAMPER, 1995: p. 117).

Tras esta dimisión, apenas se cuenta con noticias sobre la actividad de dicha institución, si bien se considera que debió ir languideciendo en el marco de la apatía de la administración, mientras sus colecciones ... se habían ido dispersando desde pocos años después de su fundación (MONTERO et alii, 1998: p. 140).

Las pocas piezas que sobrevivieron a este proceso de dispersión fueron agregadas, finalmente, al nuevo Gabinete de Historia Natural, fundado por Carlos III en I77I a raíz de la compra de la colección Franco Dávila y cuya actividad se prolonga hasta el siglo XX (CALATAYUD ARINERO, 1988; MONTERO et alii, 1998: p. 140).
Dada esta situación, cabría plantearse cuál fue el destino de las columnas de Santa Eufemia. Resulta evidente -como atestigua la documentación estudiada- que la intención del intendente era enviarlas a Madrid. Antes de la caída de Ensenada tuvo tiempo de hacerlo pero, una vez ocurrido esto, desconocemos si realmente llegaron a la capital o qué suerte corrieron, en caso de haber sido así, tras la dispersión de las colecciones de la Real Casa Geográfica.

Al respecto, tan sólo podemos apuntar una hipótesis. Pérez Bayer, en 1782, al visitar Cástulo y al referirse a la ermita y a los numerosos fragmentos de elementos arquitectónicos y columnas que se encontraban dispersos en su entorno, señalaba que

....además de las que se han roto y llevado para las eras de los cortijos inmediatos, los años pasados, un tal don Carlos Lanzi, empleado en las Fábricas de Plomo de Linares (en cuyo territorio está la ermita), se llevó a su casa dos de una grandeza formidable y que allí estuvieron algún tiempo y después se trasladaron a La Carolina, donde existen (RAH, ms. 9/5498: fol. 58r) ${ }^{9}$.

No obstante, José Martínez de Mazas, tan sólo algunos años más tarde -concretamente en 1788-, aseguraba que en el pórtico del recinto sagrado se pusieron cuatro columnas de una pieza, bien conservadas, de orden dórico con sus basas y capiteles enteros (RAH, ms, 9/5959: fol. 75v). En base a estos testimonios podemos pensar que las columnas, efectivamente, iniciaron su viaje hacia Madrid, si bien debió llegarse a un acuerdo por el que se reparó el pórtico con las cuatro columnas bien conservadas a las que se refiere el texto de Martínez de Mazas. Una vez que se produjo la caída de Ensenada, el periplo de las originales quedó abortado a medio camino entre la capital y Linares, en La

8 Esta conspiración vino motivada por las intenciones de Ensenada de construir una flota de guerra en La Habana para atacar las colonias inglesas establecidas en Belice y la Costa de los Mosquitos (Nicaragua).

9 Cortés y López, ya a principios del siglo XIX, también hace su propia apreciación sobre el tema y, aunque hay que señalar que es posible que no conociera el tema de primera mano -puesto que llega a parafrasear a Pérez Bayer-, también indica que las columnas fueron retiradas por Lanci para ser trasladadas a La Carolina ( 836: pp. 332-333). 
Carolina, donde debieron permanecer, como mínimo, hasta principios del siglo XIX.

\section{CONCLUSIONES}

Todo lo expuesto viene a poner de manifiesto hasta qué punto el auge de la Arqueología, el interés por los monumentos y las primeras medidas realmente importantes para su conocimiento y protección, fueron fruto del momento ilustrado y respondieron a unas necesidades concretas. Como ha puesto de manifiesto el artículo, una de éstas era -dentro del marco de la práctica jurídica del regalismo- la de contribuir a la creación de un sustrato intelectual que legitimase y apoyase las pretensiones de la Corona en su conflicto con la Iglesia Católica. Pero, además, hemos visto que no sólo el Patrimonio servía como argumento en este contexto, sino que -a la inversa- también los conceptos regalistas sirvieron para justificar las acciones tutelares puestas en marcha.

La inmadurez de estas prácticas, por otra parte, se hace patente si tenemos en cuenta hasta qué punto se vieron influidas por coyunturas políticas circunstanciales. Entre estas se podría hablar, por ejemplo, de la destitución de Ensenada, que llegó a suponer, como hemos señalado en algún punto del trabajo, la retirada del patrocinio Real al viaje del Marqués de Valdeflores $y$, muy probablemente, el aborto del traslado de las columnas de Santa Eufemia a Madrid. No obstante, todas estas experiencias debieron ir forjando la conciencia que desembocó en la primera norma realmente moderna para la protección de nuestro Patrimonio, la Real Cédula de I803, que como sabemos sólo fue un hito más de una la larga evolución que alcanzó hasta el siglo $X X$.

De cualquier modo, esto no evita que nos hagamos algunas preguntas que, aunque determinadas por nuestro actual punto de vista, deberían ayudarnos a conocer nuestro pasado: en realidad, ¿cuántos elementos patrimoniales debieron ser desplazados para quedar finalmente descontextualizados? Sólo un estudio pormenorizado de cada caso, podrá permitirnos, en el futuro, aproximarnos a la respuesta.

\section{FUENTES PRIMARIAS}

\section{Archivo Municipal de Linares (AML)}

FERRANT ALFONSO. Carta de confirmación en que se ratifica la sentencia dada en el pleito entre vecinos de Linares y de Baeza por la posesión del heredamiento de Cazlona. | 3 |4. CR. 003.

LIBRO de actas capitulares (|579-|59|). LA. 0004.

LIBRO de actas capitulares (1595-1599). LA. 0008.

PLEITO interpuesto por el administrador de la cofradía de la Madre de Dios de Linares, contra el intendente de minas de dicha villa, por la extracción de dos columnas de jaspe que habían formado parte del pórtico de la ermita de Santa Eufemia. 1754. Leg. 2570, exp. 3.

\section{Biblioteca de la Real Academia de la Histo- ria $(\mathrm{RAH})$}

PÉREZ BAYER, Francisco. Inscripciones y otros monumentos antiguos del manuscrito de la Universidad de Valencia: Viaje literario a Andalucía y portugal en 1782 formado por Noguera y Climent y Miguel Godínez. Manuscritos, 9/5498.

MARTÍNEZ DE MAZAS, José. Descripcion del sitio y ruinas de Castulo y noticias de esta antigua Ciudad en el Reyno de Jaen escrita Por el Lizenciado Don Josef Martinez de Mazas Canonigo Plonitenciario de la Santa Yglesia de Jaen y Governador de su Obispado. En el año de 1788 Manuscritos, 9/5959.

\section{BIBLIOGRAFÍA}

ACEDO, Manuel (1902): Cástulo: Estudio Histórico acerca de la creación, vida y existencia de esta antigua ciudad y sus relaciones con la de Linares. Madrid, Imprenta de la viuda de Tello.

ALEGRE ÁVILA, Juan Manuel (1994): Evolución y régimen jurídico del patrimonio histórico: la configuración dogmática de la propiedad histórica en la ley 16-1985, de 25 de junio, del patrimonio histórico español. Madrid, Ministerio de Cultura.

ALMAGRO-GORBEA, Martín (2010): "La Arqueología en la política cultural de la corona de España en el siglo XVIII", en ALMAGRO-GORBEA, Martín; MAIER ALLENDE, Jorge, coords.: Corona y arqueología en el siglo de las luces. Catálogo de la exposición celebrada en Madrid entre abril y julio de 2010 . Madrid, Patrimonio Nacional, pp. 35-46.

(2012): "La Arqueología en la política cultural de la corona de España en el siglo XVIII", en ALMAGROGORBEA, Martín; MAIER ALLENDE, Jorge, coords.: De Pompeya al Nuevo Mundo. La Corona española y la arqueología en el siglo XVIII. Madrid, Real Academia de la Historia y Patrimonio Nacional, pp. 17-31. 
ALMAGRO-GORBEA, Martín; MAIER ALLENDE, Jorge, coords. (2003a): 250 años de arqueología y patrimonio. Documentación sobre arqueología y patrimonio histórico de la Real Academia de la Historia. Estudio general e índices. Madrid, Real Academia de la Historia.

(2003b): "La Real Academia de la Historia y la arqueología española en el siglo XVIII", en CACCIOTI, Beatrice; DUPRÉ RAVENTÓS, Xavier; BELTRÁN FORTES, José; PALMA VENETUCCI, Beatrice, eds.: Illuminismo e ilustración: le antichità e i loro protagonisti in Spagna e in Italia nel XVIII secolo). Roma, L'Erma di Bretschneider.

BLÁZQUEZ MARTíNEZ, José María; GARCÍA GELABERT, M. Paz: Cástulo, ciudad ibero-romana. Madrid, Istmo.

BELTRÁN FORTES, José (2003): “El estamento eclesiástico en la historia de la Arqueología española del Antiguo Régimen (siglos XVI-XVIII)", en BELÉN DEAMOS, María; BELTRÁN FORTES, José, eds.: El clero y la arqueología española: Il Reunión Andaluza de Historiografía Arqueológica. Sevilla, Universidad de Sevilla.

(2009): "Del coleccionismo de antigüedades al museo público", en GONZÁLEZ PARRILLA, José María; CUENCA LÓPEZ, José María: La musealización del patrimonio. Huelva, Universidad de Huelva.

BENLLOCH POVEDA, Antonio (1984): "Antecedentes doctrinales del regalismo borbónico: juristas españoles en las lecturas de los regalistas europeos modernos", en Revista de historia moderna: Anales de la Universidad de Alicante. $N^{\circ}$ 4. Alicante, Universidad de Alicante, pp. 293-322.

CABALLERO ZOREDA, Luis; SÁNCHEZ SANTOS, J. C. (1990): "Reutilizaciones de material romano en edificios de culto cristiano", en Antigüedad y cristianismo: Monografias históricas sobre la Antigüedad tardía. № 7. Murcia, Universidad de Murcia, pp. 431-486.

CÁLAMA RODRÍGUEZ, José María; GRACIANI GARCÍA, Amparo (1998): La restauración decimonónica en España. Sevilla, Universidad de Sevilla, Instituto Universitario de Ciencias de la Construcción.

CALATAYUD ARINERO, María de los Ángeles (1986): "Antecedentes y creación del Real Gabinete de Historia Natural de Madrid", en Arbor: Ciencia, pensamiento y cultura. $N^{\circ}$ 482. Madrid, CSIC, pp. 9-34.

(1988): Pedro Franco Dávila: Primer director del Real Gabinete de Historia Natural fundado por Carlos III. Madrid, Museo Nacional de Ciencias Naturales.

CASTILLO ARMENTEROS, Juan Carlos (1998): La Campiña de Jaén en Época Emiral (s. VIII-V). Jaén, Universidad de Jaén.

CHOCLÁN SABINA, Concepción et alii (2008-2009): Memoria. "BEROS" Intervención Arqueológica con la Escuela Taller "Ruta de los Iberos ", en la Zona Arqueológica de Cástulo. Inédito.

CORTÉSY LÓPEZ, Miguel ( I 836): Diccionario GeográficoHistórico de la España Antigua, Tarraconense, Bética y Lusitana, con la correspondencia de sus regiones, ciudades, montes, ríos, caminos, puertos e islas conocidos en nuestros días. Tomo II. Madrid, Imprenta Real.
ECHEVARRÍA ARSUAGA, Ana (2003): "La transformación del espacio islámico (siglos XI-XIII)", en Annexes des Cahiers de linguistique et de civilisation hispaniques médiévales. Vol. 15. Lyon, Séminaire d'Études Médiévales Hispaniques, pp. 53-77.

FATÁS, Guillermo; BORRÁS, Gonzalo (1988): Diccionario de términos de Arte y elementos de Arqueología, Heráldica y Numismática. Madrid, 1990, Alianza.

GONZÁLEZ-VARAS, Ignacio (1999): Conservación de Bienes Culturales. Teoría, historia, principios y normas. Madrid, 2008, Cátedra.

LLULL PEÑALBA, Josué (2005): "Evolución del concepto y de la significación social del patrimonio cultural", en Arte, individuo y sociedad. N. 17. Madrid, Universidad Complutense de Madrid, pp. 177-208.

LÓPEZ-CORDÓN, M. Victoria (20I0): "La Corona y la irradiación de la cultura española", en ALMAGROGORBEA, Martín; MAIER ALLENDE, Jorge, eds.: Corona y Arqueología en el Siglo de las Luces, exposición celebrada en Madrid entre abril y julio de 20 I0. Madrid, Patrimonio Nacional, pp. 19-33.

MAIER ALLENDE, Jorge (2003): "El II centenario de la Real Cédula de 1803. La Real Academia de la Historia y el inicio de la legislación sobre el patrimonio arqueológico y monumental en España", en Boletín de la Real Academia de la Historia.Tomo 200, cuaderno 3. Madrid, Real Academia de la Historia, pp. 440-473.

(2010): "Renovación e institucionalización de la investigación arqueológica en el reinado de Fernando $\mathrm{VI}$ (I746- 1759)", en ALMAGRO-GORBEA, Martín; MAIER ALLENDE, Jorge, coords:: Corona y arqueología en el siglo de las luces. Catálogo de la exposición celebrada en Madrid entre abril y julio de 2010. Madrid, Patrimonio Nacional, pp. I47-I57.

(20।0): "La Corona y la institucionalización de la Arqueología en España", en ALMAGRO-GORBEA, Martín; MAIER ALLENDE, Jorge, coords.: De Pompeya al Nuevo Mundo. La Corona española y la arqueología en el siglo XVIII. Madrid, Real Academia de la Historia y Patrimonio Nacional, pp. 333-360.

MONTERO, Ángel; DIÉGUEZ, Carmen (1998): "La Paleontología en el Real Gabinete de Historia Natural en los siglos XVIII y XIX (I77|-1895)", en Boletín de la Real Sociedad Española de Historia Natural, Sección Geología. No 94. Madrid, Real Sociedad Española de Historia Natural, pp. 139-148.

MORA RODRÍGUEZ, Gloria (1998): Historias de Mármol. La arqueología clásica española en el siglo XVIII. Madrid, Polifemo.

MORALES, Ambrosio de (I575): Las antigüedades de las ciudades de España: que van nombradas en la corónica con las averiguaciones de sus sitios y nombres antiguos. Primera parte. Valencia, 200 I, Librerías París-Valencia.

MUÑOZ COSME, Alfonso (1989): La conservación del patrimonio histórico español. Madrid, Ministerio de Cultura. 
ORTEGA y SAGRISTA, Rafael (1977): "Venerable antigüedad de las cofradías pasionistas de Linares", en Boletín del Instituto de Estudios Giennenses. Nº 92. Jaén, Instituto de Estudios Giennenses.

PANIAGUA SOTO, José Ramón (1978): Vocabulario básico de Arquitectura. Madrid, 2005, Cátedra.

PELLETIER, Agnes (1987): "Cástulo et la conquete", en Gerión. № 5. Madrid, Universidad Complutense de Madrid.

PONZ, Antonio (|79|): Viage de España, en que se da noticia de las cosas apreciables y dignas de saberse que hay en ella. Tomo XVI. Madrid. Viuda de Don Joaquín Ibarra.

PUIG-SAMPER, Miguel Ángel (1995): "Antonio de Ulloa, naturalista", en LOSADA, Miguel;VARELA, C.: Actas del II centenario de Antonio de Ulloa. Sevilla, Escuela de Estudios Hispanoamericanos, pp. 97-124.

QUIROSA GARCÍA, M. Victoria (2008): "El nacimiento de la conciencia tutelar. Origen y desarrollo en Europa durante el siglo XVIII", en e-rph. Revista electrónica de patrimonio Histórico. № 2. Granada, Universidad de Granada, pp. 17-35.
RAE. A. ( I734): Diccionario de la lengua castellana, en que se explica el verdadero sentido de las voces, su naturaleza y calidad, con las phrases o modos de hablar, los proverbios o refranes, y otras cosas convenientes al uso de la lengua [...]. Compuesto por la Real Academia Española. Tomo quarto. Que contiene las letras G.H.I.J.K.L.M.N. Madrid, Imprenta de la Real Academia Española, por los herederos de Francisco del Hierro.

SALAS ÁLVAREZ, Jesús (2007): "Coleccionismo erudito en la Andalucía de la llustración: los depósitos eclesiásticos de antigüedades", en mus-A. $N^{\circ}$ 8. Sevilla, Junta de Andalucía.

SALVATIERRA CUENCA, Vicente (200I): La crisis del Emirato Omeya en el Alto Guadalquivir: precisiones sobre la geografía de la rebelión muladí. Jaén, Universidad de Jaén.

TORTOSA ROCAMORA, Trinidad; MORA RODRÍGUEZ, Gloria (1996): "La actuación de la Real Academia de la Historia sobre el patrimonio arqueológico: ruinas y antigüedades", en Archivo Español de Arqueología. Vol. 69, N 173-174. Madrid, CSIC, pp. 191-218.

YÁÑEZVEGA, Ana; LAVÍN BERDONCES, Ana C. (1999): "La legislación española en materia de Arqueología hasta 1912: análisis y evolución en su contexto", en Patrimonio Cultural y Derecho. No 3. Madrid, Hispania Nostra, pp. |23-| 45 . 